\title{
The reports of lesions in kidney and intestine of apparently normal cultured silver carp (Hypophtalmictys molitrix)
}

\author{
Mahsa Jafarizadeh ${ }^{1}$, Rahim Peyghan ${ }^{2}$, Babak Mohammadian ${ }^{2}$ \\ ${ }^{1}$ Department of Fisheries, Islamic Azad University Ahvaz Branch, Ahvaz, Iran \\ ${ }^{2}$ Veterinary Faculty, Shahid Chamran University, Ahvaz, Iran \\ Email: jafarizadeh_fishery@yahoo.com
}

Received 21 January 2012; revised 27 February 2012; accepted 4 March 2012

\begin{abstract}
Among fresh water fishes, silver carp because of fast growth rate and desired meat quality, is a dominant species in polyculture systems in Iran. This fish mainly feed on phytoplankton. In present survey kidney and intestine of 120 silver carp (Hypophthalmichtys molitrix) from 4 regions in Khuzestan province-Iran have been studied. Tissue samples were provided from kidney and intestine and sectioned by routine method after paraffin embedding and finally stained with hematoxilin and eosin ( $H \&$ E). The microscopic results were analyzed qualitatively and quantitatively. Microscopical analysis showed that kidney tissue had lesions including: edema, necrosis, uroliths, hemorrhage and degeneration. In different regions, fishes showed different prevalence of lesions. Edema and urolith were the most prevalent lesions ( 30 and 25 percent respectively). In histometric analysis the diameter of layers of intestine in some of the fish farms were significantly higher than the other regions. This increase was because of increase in muscular layer. The intensity of all lesions was estimated as light according to distribution of lesions. The probable cause of these lesions may be the high stocking density, intoxication, water quality problem such as excessive carbon dioxide. The only lesion in intestine was the excessive proliferation of mucus cells that this lesion may be created due to the improper plankton diet.
\end{abstract}

Keywords: Lesions; Kidney; Intestine; Silver Carp; Hypophtalmictys molitrix

\section{INTRODUCTION}

Carps (common carp and three species of Chinese carps including silver carp) are the mainstay of Iranian aquaculture especially in Khuzestan province, contributing over $95 \%$ to the total fish production in this region. Carp culture has a great potential for many region of the world due to high market value and lower cost of feeding in comparison with other fish species [1]. From the point of nutrition and importance in aquaculture industry, this species is filter feeder, not capable of dealing with a mixed diet, phytoplanktonvorous [2]. In polyculture of warm water fishes, silver carp is a main species (more than 50\%) [3]. There are many unpublished health problem for silver carps in semi-intensive fish culture in Iran and other countries. Histology was used as a health indicator in many fish species [4-8]. In recent years a series of mortality was observed in silver carp of Khuzestan province. The present work is a preliminary study attempting to investigate the prevalence of lesion as well as to study the structure of the alimentary canal and kidney in silver carp.

\section{MATERIALS AND METHODS}

\subsection{Fish Sampling}

In this research 120 cultured silver carp were caughtin autumn when they having a market weight (Table 1) from 4 regions. Those fish farms in khozestan is located, incloud Ahvaz, Shoshtar, Dezfol and Khoramshahr. From each site 30 fishes were caught randomly by using fish net. The fish were anesthetized by a blow to the head and the total length and weight of each fish was measured. After opening the abdomen, samples from the intestine and kidneys were taken and fixed in buffered $10 \%$ formalin.

\subsection{Procedures for Histology}

A $1 \mathrm{~cm}^{3}$ portion of posterior kidney and middle part of intestine was placed in $10 \%$ neutral buffered formalin. Tissues were processed routinely using standard histological techniques and embedded in paraffin. Hematoxylin and eosin was used for tissues staining.

\subsection{Data Analysis}

For micrometric measurement we used Sa-iran micro- 
Table 1. Total length and weight of sampled silver carps (Hypophtalmichtys molitrix) from four regions.

\begin{tabular}{ccc}
\hline Region & Total length $(\mathbf{c m})$ & Weight $(\mathbf{g})$ \\
\hline Khoramshahr & $55 \pm 2$ & $1976 \pm 317$ \\
Shoshtar & $46 \pm 1$ & $955 \pm 125$ \\
Dezfol & $39 \pm 2$ & $647 \pm 110$ \\
Ahvaz & $51 \pm 2$ & $1502 \pm 155$ \\
\hline
\end{tabular}

scope camera and axiovision software. For data analysis SPSS-17 software and one-way ANOVA was used to compare the means. Finally, graphs were drawn with excel 2010 software. Meanwhile data were presented as mean \pm standard deviation.

\section{RESULTS}

\subsection{Histopathologic Study}

After the preparation of tissue sections from kidney and intestine, they have been studied qualitatively and quantitatively from histologic condition. Percentage of lesions of tissues in the studied groups is shown in Table 2 and Figure 1. Microscopic results showed that the kidney tissue of sampled fish has lesions including edema, necrosis, degeneration, kidney stone and hemorrhage (Figures 2-7).

These lesions showed different prevalence in different areas. The highest prevalence value of kidney stone and edema observed in around Dezfol that respectively in 30 and 25 percent of fishes. The highest value of degeneration lesions $(40 \%)$ and the highest percent of necrosis (35\%) observed in around Ahvaz. The only observed lesion in intestine sampled fish was increasing in gablet cells. In this study, the intensity of all lesions was estimated light lesions.

\subsection{Histometric Study}

The average of intestine layers diameter, glomerulus diameter, epithelial cell diameter of tubules and kidney tubules diameter were measured by micrometery method and amounts were compared with each other and can be seen in Tables $\mathbf{3}$ and $\mathbf{4}$. In histometric survey, increase in intestine layers diameter was observed in farmed fishes around Ahvaz. The reason of this condition was increase in muscular layer diameter. But mucos layer don't show significantchange between regions (Figures 8-13).

\section{DISCUSSION}

With microscopic study of kidney in silver carps in different region of Khuzestan province the lesions that observed were degeneration, edema, hemorrhage, necrosis and kidney stone. Although these lesions were not fatal but every of them can be an indicator of a disorder in fish
Table 2. Prevalance of kidney lesions in silver carp (Hypophtalmichtys molitrix) in different studied regions: field 1 (Khoramshahr), field 2 (Shoshtar), field 3 (Dezfol), field 4 (Ahvaz).

\begin{tabular}{cccccc}
\hline $\begin{array}{c}\text { lesions } \\
\text { region }\end{array}$ & Necrosis & Hemorrhage & Edema & Degeneration & $\begin{array}{c}\text { Kidney } \\
\text { stone }\end{array}$ \\
\hline Field 1 & 0 & 5 & 10 & 20 & 0 \\
Field 2 & 0 & 15 & 15 & 25 & 10 \\
Field 3 & 10 & 15 & 25 & 35 & 30 \\
Field 4 & 35 & 10 & 15 & 40 & 25 \\
\hline
\end{tabular}

Table 3. Average amount of silver carp intestine tissue (Mean \pm S.D.) according to micrometer-explanation: field 1 (Khoramshahr), field 2 (Shoshtar), field 3 (Dezfol), field 4 (Ahvaz).

\begin{tabular}{cccc}
\hline parameter & $\begin{array}{c}\text { Mucus layer } \\
\text { diameter }\end{array}$ & $\begin{array}{c}\text { Intestine layer } \\
\text { diameter }\end{array}$ & $\begin{array}{c}\text { Muscular layer } \\
\text { diameter }\end{array}$ \\
\hline Field 1 & $287 \pm 101^{*}$ & $437 \pm 110$ & $133 \pm 36$ \\
Field 2 & $305 \pm 77$ & $425 \pm 98$ & $115 \pm 24$ \\
Field 3 & $351 \pm 375$ & $395 \pm 80$ & $127 \pm 34$ \\
Field 4 & $303 \pm 99$ & $481 \pm 111$ & $167 \pm 52$ \\
\hline
\end{tabular}

*Note: There was significant difference between regions.

Table 4. Average amount of silver carp kidney tissue (Mean \pm S.D.) - explanation: field 1 (Khoramshahr), field 2 (Shoshtar), field 3 (Dezfol), field 4 (Ahvaz).

\begin{tabular}{cccc}
\hline parameter & $\begin{array}{c}\text { Layers diameter } \\
\text { (micrometer) }\end{array}$ & $\begin{array}{c}\text { Kidney tubule } \\
\text { diameter } \\
\text { (micrometer) }\end{array}$ & $\begin{array}{c}\text { Glomerulus } \\
\text { diameter } \\
\text { (micrometer) }\end{array}$ \\
\hline Field 1 & $10.41 \pm 1.8$ & $29.17 \pm 4.38$ & $38.48 \pm 4.50$ \\
Field 2 & $10.9 \pm 2.35$ & $28.22 \pm 5.48$ & $34.70 \pm 6.38$ \\
Field 3 & $10 \pm 1.52$ & $25.96 \pm 3.95$ & $35.59 \pm 7.08$ \\
Field 4 & $10.07 \pm 1.65$ & $26.55 \pm 3.88$ & $37.24 \pm 5$ \\
\hline
\end{tabular}

*There was no significant difference between regions.

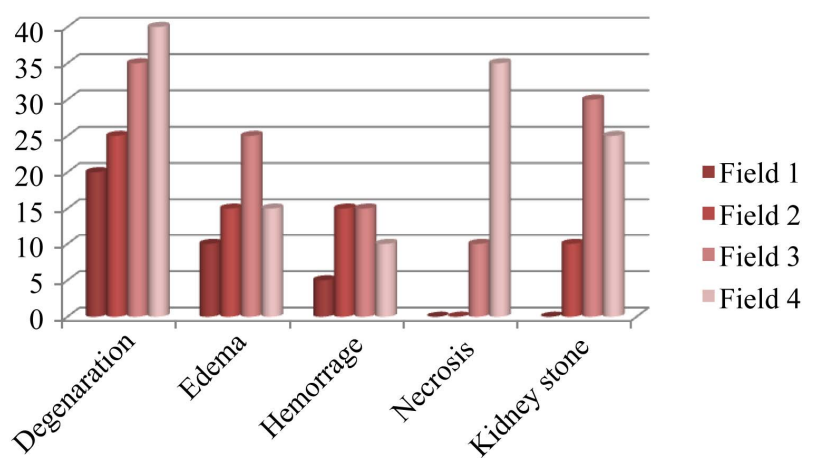

Figure 1. Prevalance of kidney lesions in silver carp (Hypophtalmichtys molitrix) in different studied regions: field 1 (Khoramshahr), field 2 (Shoshtar), field 3 (Dezfol), field 4 (Ahvaz). 


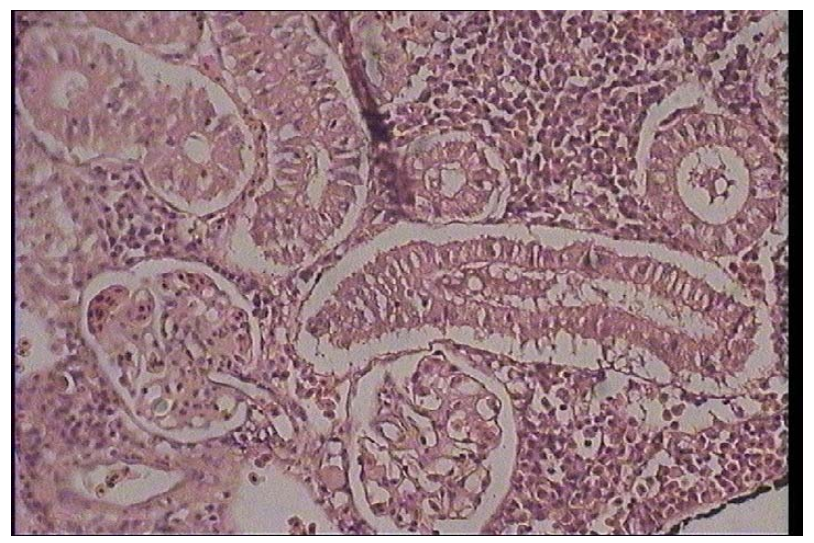

Figure 2. Degeneration in kidney tubules of silver carp (Hypophtalmichtys molitrix) (H \& E) magnification: $\times 400$.

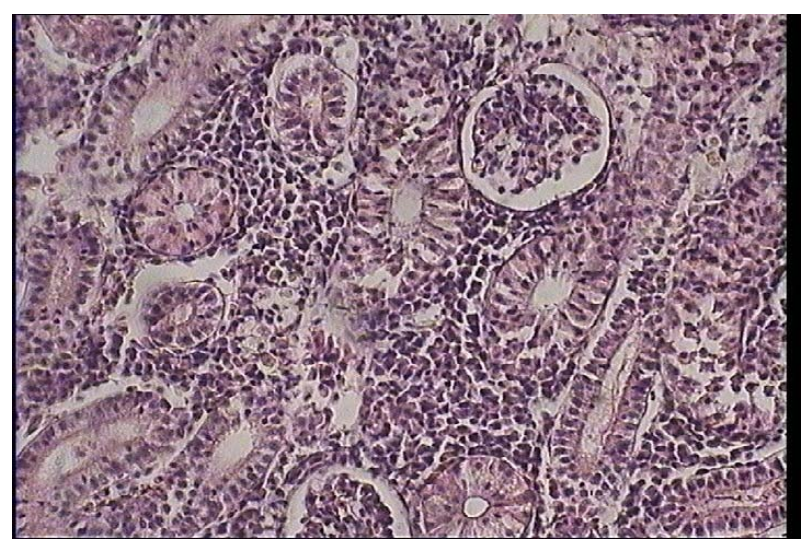

Figure 3. Edema in kidney glomeruli of silver carp (HypophtaImichtys molitrix) (H \& E) magnification: $\times 400$.

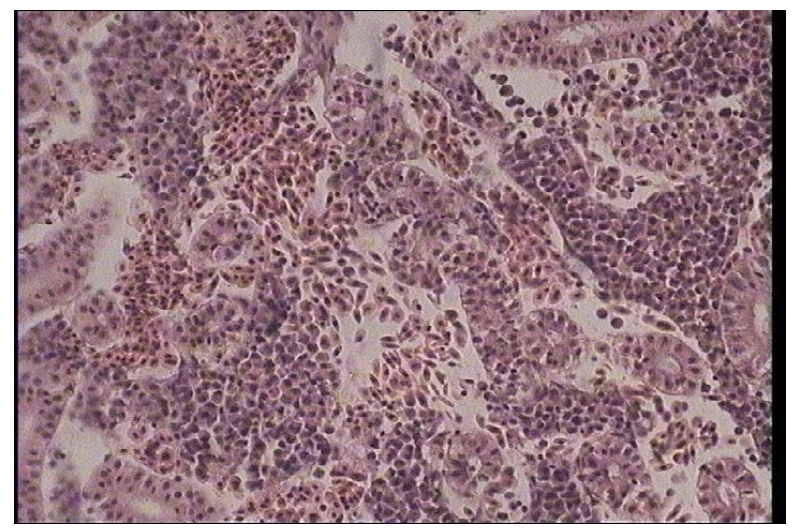

Figure 4. Hemorrhage in kidney interstitial tissues of silver carp (Hypophtalmichtys molitrix) (H \& E) magnification: $\times 400$.

body or farm pond. Degeneration and edema lesions could be reversible but the other lesions are nonreversible and can be a sign of intense problem in fish. In this study all of the lesions assessed as light. These lesions showed different abundance in different region. The highest abundance rate of kidney stone and edema that was observed in Dezfol region in fish was 30 and 25

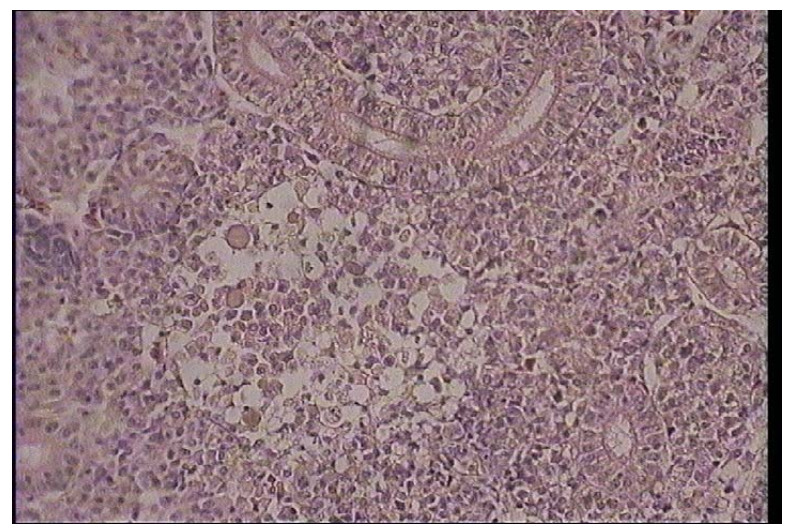

Figure 5. Necrosis in kidney interstitial tissues of silver carp (Hypophtalmichtys molitrix) (H \& E) magnification: $\times 400$.

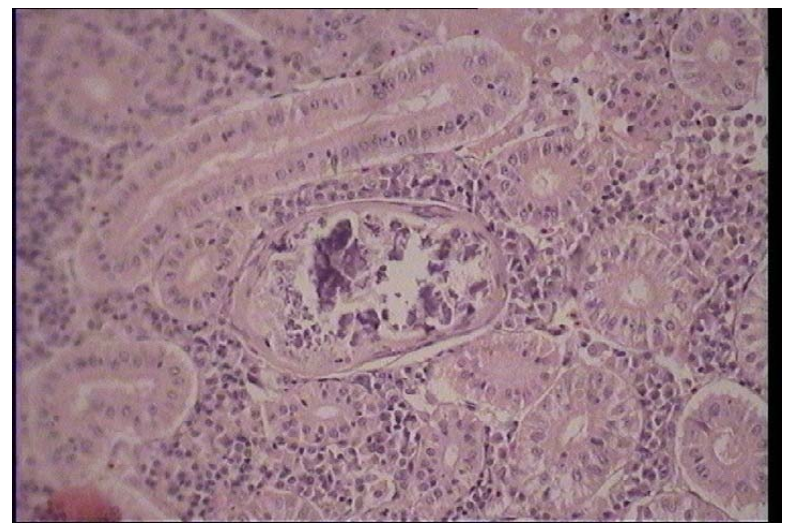

Figure 6. Urolith (stone) in kidney tubules of silver carp (Hypophtalmichtys molitrix) (H \& E) magnification: $\times 400$

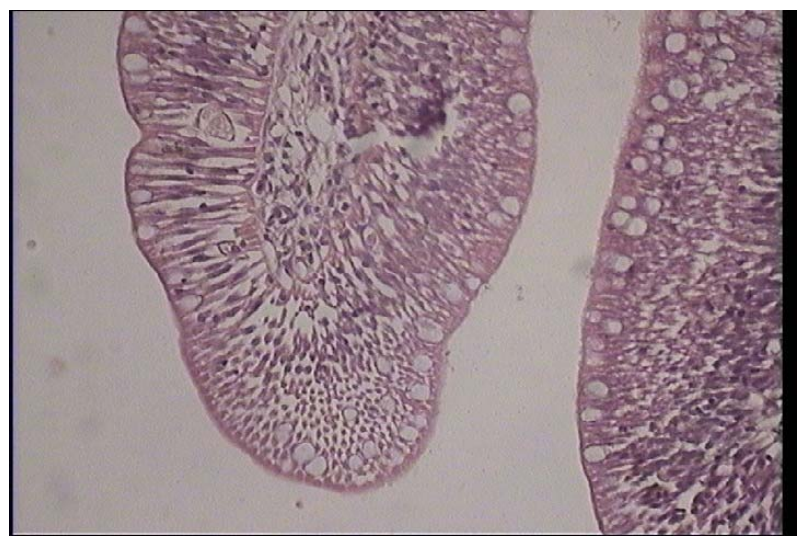

Figure 7. Proliferation of gablet cells of silver carp (HypophtaImichtys molitrix) (H \& E) magnification: $\times 400$.

percent respectively.

Kidney stone is one of kidney disorder that generally emerges in fresh water and marine aquaculture because of high fish density. The intense form of kidney stone usually was seen in intensive fish culture because of high $\mathrm{CO}_{2}$ level. This factor may lead to metabolic acidosis and calcium deposit in kidney. The other reason for this con- 
dition may be a disproportionate balance between calcium and magnesium in fish diet. Most ground (well or spring) water has dissolved carbonates and carbon dioxide in them and $\mathrm{pH}$ between 5 and 8. Ground water in contact with silicate minerals is poorly buffered and typically has a low $\mathrm{pH}$ and a large amount of $\mathrm{CO}_{2} \mathrm{com}-$ pared to ground water taken from carbonate substrate that is thus well buffered [9]. In a pond, $\mathrm{pH}$ is highly influenced by the soil type. Acid sulfate soils may have a $\mathrm{pH}$ less than 4 because of the oxidation of sulfide to sulfuric acid, making them unsuitable for fish culture unless neutralized. Waters impacted by acid rain or that drain acidic soils may have low $\mathrm{pH}$. This can be a problem in a raceway culture after a rain, when large amounts of acids are washed into a stream water supply. The metabolic activity of fish and other aquatic organisms produces acids. In a closed system, such as an aquarium or pond, these acids tend to gradually reduce $\mathrm{pH}$.

The highest rate of kidney degeneration (40\%) and necrosis (35\%) has been observed in Ahvaz. Blood purification is a selective and specific function that does by glomeruliblood capillaries. For this reason microscopic changes in intoxication may be observed in them. Necrosis in kidney cells showed a highest rate in Ahvaz region that probable reason from this could be poisoning. In intense degeneration it may lead to necrosis in form of piknosis and vacuolization of cytoplasm. In this case, eosinophil particle maybe built in cell or create secondarily by absorption of protein materials from glomeruli.

Hemorrhage observed in silver carps kidneys. Kidney hemorrhage could represent by trauma or blood vessel disorders. We can say that the reasons of existence this lesions in farmed silver carps poising with heavy metal, changes in water $\mathrm{pH}$, high density, probable impacts, diet disproportionately and chemical, industry pollutions and algae bloom. The posterior kidney, which produces large amounts of dilute urine in freshwater fish, is susceptible to the toxic effects of organic chemicals. Nephrotoxic lesions, including degenerative changes (e.g. vacuolization) and desquamation of the tubular epithelium, dilation of the tubular lumina, and necrosis of tubular epithelium have been noted in fish exposed to PCBs, organochlorine and organophosphate insecticides, herbicides, petroleum hydrocarbons and phenols. Glomerular hyalinosis was seen in the kidneys of medaka (Oryzias latipes) exposed to the organochlorine insecticide, Lindane. Medaka and guppies (Poecilia reticulata) exposed to organotin compounds developed degeneration of tubular epithelium and inflammatory glomerular lesions. Cytoplasmic vacuolization, necrosis and ultrastructural changes were noted in the epithelial cells of the renal tubules of goldfish (Carassius auratus) exposed to hexachlorobutadiene [10, 11].

Hypoxic episodes in south-east Kattegat have been

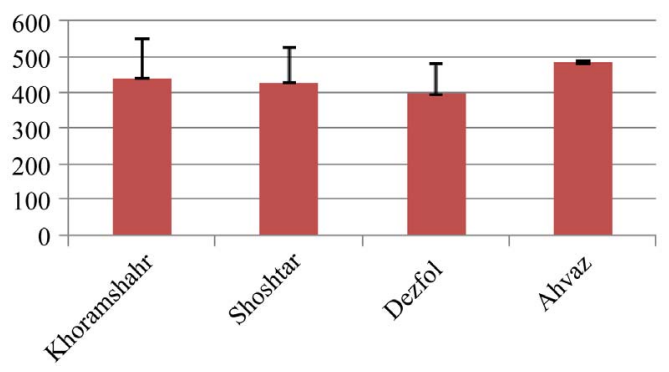

Figure 8. Intestine layers diameter in 4 studied region (micrometer)-explanation: field 1 (Khoramshahr), field 2 (Shoshtar), field 3 (Dezfol), field 4 (Ahvaz).

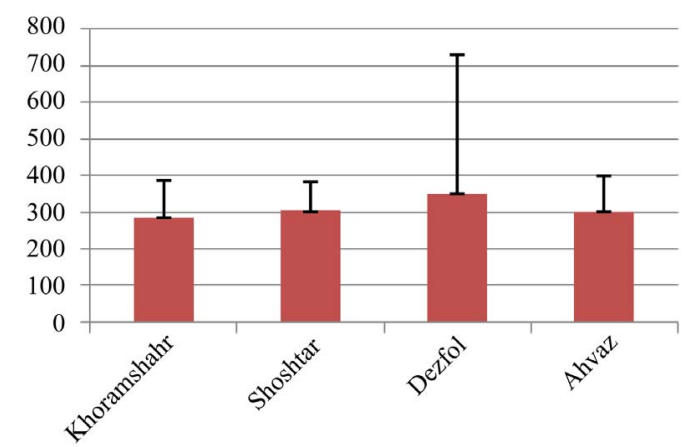

Figure 9. Intestine mucus layers diameter in 4 studied region (micrometer) — explanation: field 1 (Khoramshahr), field 2 (Shoshtar), field 3 (Dezfol), field 4 (Ahvaz).

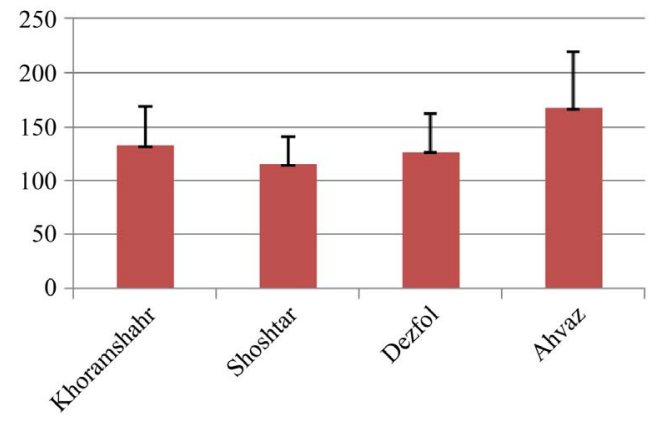

Figure 10. Intestine muscular layers diameter in 4 studied region (micrometer) - explanation: field 1 (Khoramshahr), field 2 (Shoshtar), field 3 (Dezfol), field 4 (Ahvaz).

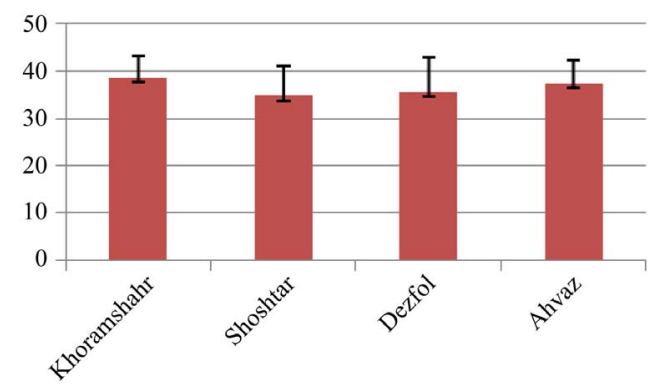

Figure 11. Kidney glomerulus diameter in 4 studied region (micrometer) — explanation: field 1 (Khoramshahr), field 2 (Shoshtar), field 3 (Dezfol), field 4 (Ahvaz). 


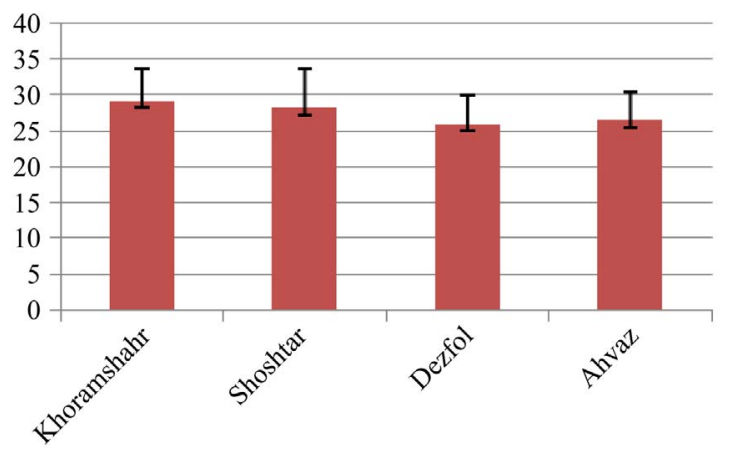

Figure 12. Kidney tubule diameter in 4 studied region (micrometer) — explanation: field 1 (Khoramshahr), field 2 (Shoshtar), field 3 (Dezfol), field 4 (Ahvaz).

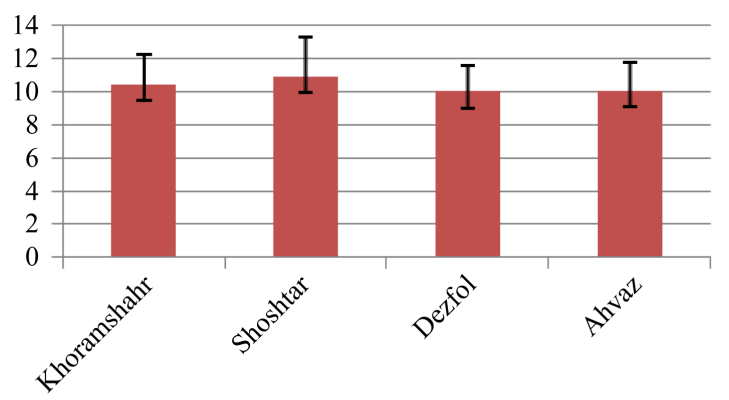

Figure 13. Kidney tubule epithelial cells diameter in 4 studied region (micrometer) - explanation: field 1 (Khoramshahr), field 2 (Shoshtar), field 3 (Dezfol), field 4 (Ahvaz).

correlated with the abundance of smaller fishes, indicating that hypoxia also limits growth under natural conditions. Also, a recorded decrease in growth in fish was found to be correlated with an occasional decrease in dissolved oxygen levels [12]. Under natural conditions, hypoxia is likely to occur in combination with hypercapnia and will often be associated with elevated $\mathrm{CO}_{2}$ and could be used as a histochemical marker for toxic effects in fish kidney [13].

Many chemicals exist in different forms (chemical species) as a result of chemical and biochemical reactions. The identities and relative concentrations of chemical species vary with location and time and differ among the components of an aquatic ecosystem [14,15]. A fish can be exposed to a mixture of chemical species both in the water it contacts and in the food it ingests. Chemical accumulation and toxicity depend not just on total chemical concentration in the environment but also on how readily the fish can absorb these different chemical species at the gill, across the skin, and within the digestive tract and on how chemical speciation affects distribution throughout the organism [16].

Ammonia is usually not a problem unless supplemental aeration is used preventing environmental hypoxia and thus allowing higher fish densities. As in other sys- tems, feeding (uneaten, decaying food and ammonia generated from food consumption or dead fish) is the largest source of ammonia in a commercial pond. Ammonia may also rise after an algae crash or massive die-off; this not only reduces ammonia assimilation but also adds to ammonia buildup caused by the decaying algae [17].

In conclusion there are many lesions in kidneys of apparently normal silver carp that the intensity of all lesions was estimated as light according to distribution of lesions. The probable cause of these lesions may be the high stocking density, intoxication, water quality problem such as excessive carbon dioxide. The only reported intestinal lesions in silver carps was increase in mucos cells that seen 2 case in Ahvaz and 1 case in Khouramshahr. This only lesion in intestine may be created by the excessive proliferation of mucus cells and may be caused by the improper plankton diet.

\section{REFERENCES}

[1] Sehgal, H.S. and Sehgal, G.K. (2002) Aquacultural and socio-economic aspects of processing carps into some value-added products. Bioresource Technology, 82, 291293. doi:10.1016/S0960-8524(01)00182-1

[2] Asgharzadeh, A., Shabanpour, B., Aubourg, S.P. and Hosseini, H. (2010) Chemical changes in silver carp (Hypophtalmichthys molitrix) minced muscle during frozen storage: Effect of washing process. Fisheries Department, Agriculture and Natural Resources University, Gorgan.

[3] Iinuma, M., Sharma, K.R. and Leung, P.S. (1999) Technical efficiency of carp pond culture in peninsula Malaysia: An application of stochastic production frontier and technical inefficiency model. Aquaculture, 175, 199-213. doi:10.1016/S0044-8486(99)00033-2

[4] Ahmed, M.S. (2009) Effect of different artificial diets on growth rate condition and histogical structure of Nile tilapia. Research Journal of Fisheries and Hydrobiology, 4, 29-34.

[5] Cengiz, I. (2006) Gill and kidney histopathology in the freshwater fish Cyprinus carpio after acute exposure to deltamethrin. Environmental Toxicology and Pharmacology, 22, 200-204. doi:10.1016/j.etap.2006.03.006

[6] Delashoub. M., Pousty, H. and Khojasteh Banam, S.M. (2010) Histology of bighead carp intestine. Global Veterianaria, 5, 302-306.

[7] Kuperman, B.I. and Kuzmina, V.V. (1996) Structure and function of intestinal epithelium in freshwater teleosts with different types of feeding. International Congress on the Biology of Fish, San Francisco.

[8] Ke, Z.X., Ping, X. and Guo, L.G. (2008) Phenotypic plasticity gut length in the planktivorous filter-feeding silver carp (Hypophtalmichthys molitrix). The Scientific World Journal, 8, 169-175. doi:10.1100/tsw.2008.37

[9] Woo, P.T.K. (1995) Fish diseases and disorders vol. 3: Viral, bacterial and fungal infections. CABI Publishing, 
Oxon.

[10] Stoskopf, M.K. (1993) Fish medicine. W.B. Sannders, Philadelphia.

[11] Silva, A.G. and Martinez, C.B.R. (2007) Morphological changes in the kidney of a fish living in an urban stream. Environmental Toxicology and Pharmacology, 23, 185192. doi:10.1016/j.etap.2006.08.009

[12] Mares, J., Palikova, M., Kopp, R., Navratil, S. and Pikula, J. (2009) Changes in the nutritional parameters of muscles of the common carp (Cyprinus carpio) and the silver carp (Hypophtalmichthysmolitrix) following environmental exposure to cyanobacterial water bloom. Aquaculture Research, 40, 148-156. doi:10.1111/j.1365-2109.2008.02074.x

[13] Melaa, M., Randia, M.A.F., Venturab, D.F., Carvalhoc, C.E.V., Pelletierd, E. and Oliveira Ribeiroa, C.A. (2007) Effects of dietary methylmercury on liver and kidney histology in the neotropical fish Hoplias malabaricus. Ecotoxicology and Environmental Safety, 68, 426-435. doi:10.1016/j.ecoenv.2006.11.013
[14] Xie, P., Chen, J., Zhang, D., Ke, Z. and Yang, H. (2006) In situ studies on the bioaccumulation of microcystins in the phytoplanktivorous silver carp (Hypophthalmichthys molitrix) stocked in Lake Taihu with dense toxic Microcystis blooms. Aquaculture, 261, 10261038.

[15] Domaizon, I. and Dévaux, J. (1999) Impact of moderate silver carp biomass gradient on zooplankton communities in a eutrophic reservoir. Consequences for the use of silver carp in biomanipulation. Life Sciences, 322, 621-628.

[16] Couillard, C.M., Williams, P.J., Courtenay, S.C. and Rawn, G.P. (1999) Histopathological evaluation of Atlantic tomcod (Microgadus tomcod) collected at estuarine sites receiving pulp and paper mill effluent. Aquatic Toxicology, 44, 263-278. doi:10.1016/S0166-445X(98)00085-X

[17] Benli, A., Koksal, G. and Ozkul, A. (2008) Sublethal ammonia exposure of Nile tilapia (Oreochromis niloticus): Effects on gill, liver and kidney histology. Chemosphere, 72, 1355-1358. doi:10.1016/j.chemosphere.2008.04.037 